Int. J. Dev. Biol. 56: 385-391 (2012)

doi: $10.1387 / \mathrm{ijdb} .113475 \mathrm{dn}$

\title{
Expression of serotonergic system components during early Xenopus embryogenesis
}

\author{
DENIS A. NIKISHIN ${ }^{1}$, STANISLAV V. KREMNYOV ${ }^{2}$, VICTORIA V. KONDUKTOROVA ${ }^{3}$ and YURI B. SHMUKLER ${ }^{*, 1}$ \\ ${ }^{1}$ Koltzov Institute of Developmental Biology, Russian Academy of Sciences, Group of Embryophysiology, \\ ${ }^{2}$ Lomonosov Moscow State University, Faculty of Biology, Department of Embryology, Laboratory of Developmental \\ Biophysics and ${ }^{3}$ Engelhardt Institute of Molecular Biology, Russian Academy of Sciences, Laboratory of Molecular \\ Biology of Development, Moscow, Russia
}

\begin{abstract}
Despite abundant research studies on the physiological and biochemical nature of embryonic neurotransmitter function, little is known about the molecular genetic mechanisms involved. The expression of the main components of the serotonergic system during early Xenopus embryogenesis was investigated using RT-PCR, real time PCR and in situ hybridization. Transcripts encoding the serotonin receptors HTR2C and HTR7, as well as the vesicular monoamine transporter VMAT2, the serotonin transporter (SERT) and the serotonin synthesis enzymes tryptophan hydroxylase (TPH2) and aromatic amino acid decarboxylase (AAAD) were found to be expressed during the cleavage division stages, whereas the degradation enzyme monoamine oxidase $A$ (MAOA) was absent. The main components of the serotonergic system were found to be expressed during the earliest stages of embryonic development. The embryonic transmitter mechanism, its complexity, and its variability among various species are discussed.
\end{abstract}

KEY WORDS: serotonin, receptor, transporter, embryo, Xenopus

The presence and functional activity of the substances known as classic neurotransmitters (serotonin, acetylcholine, adrenaline and dopamine) during embryogenesis were first investigated by Buznikov and his collaborators (see Buznikov, 1967). Since then, it has become clear that the physiological functions of these substances are not limited to synaptic transmission and persist throughout ontogenesis, including the very early stages (see Shmukler, Buznikov, 1998; Buznikov, 2007).

The serotonergic system is one of the most intensively studied transmitter systems in early embryogenesis. It was demonstrated that serotonin (5-HT) is involved in cell cycle control, the regulation of the cytoskeleton state, and blastomere interactions during cleavage divisions (Shmukler, Buznikov, 1998). During the later stages of development, serotonin is involved in the regulation of ciliary motility, gastrulation, the establishment of left-right asymmetry, morphogenetic processes, metamorphosis, and organogenesis (Buznikov, 1990; Fukumoto et al., 2005b). However, there is sparse molecular genetic data on the prenervous serotonin mechanisms (Vesela et al., 2003; Dube, Amireault, 2007; see also Table 1).

The aim of the present work is to comprehensively examine the expression of serotonergic system components in $X$. laevis embryos. The presence of serotonin and its functional activity
(Fukumoto et al., 2005b) in Xenopus embryos allows for the investigation of the expression of serotonin receptors HTR1A, HTR2B, HTR2C, HTR3A, HTR4, HTR7. Our analysis of the serotonergic system also encompasses the study of monoamine vesicular transporters VMAT1 and VMAT2, sodium-dependent serotonin transporter (SERT), enzymes involved in serotonin synthesis (tryptophan hydroxylases TPH1 and TPH2, and aromatic aminoacid decarboxylase (AAAD)), and degradation (monoamine oxidase A (MAOA)).

This work contributes to the systematic study of the prenervous transmitter system during early embryogenesis of various animal species.

\footnotetext{
Abbreviations used in this paper: 5-HT, serotonin; AAAD, aromatic aminoacid decarboxylase; AC, animal cap; EST, expressed sequence tag; HTR, serotonin receptor; ISH, in situ hybridization; MAOA, monoamine oxidase A; MMR, Marc's modified Ringer's; MZ, marginal zone; nAChR, nicotinic acetylcholine receptor; ODC, ornithine decarboxylase; RT-PCR, reverse transcription polymerase chain reaction; SERT, serotonin transporter; TPH, tryptophan hydroxylase; VMAT, vesicular monoamine transporter; VP, vegetal pole fragment; $\beta$-AdR, $\beta$-adrenoreceptor.
}

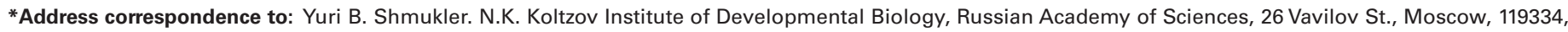
Russia. Fax: +7-499-135-8012.Tel: +7-499-135-0052. e-mail: yurishmukler@yahoo.com - web: idbras.comcor.ru/indexr.HTM
} 


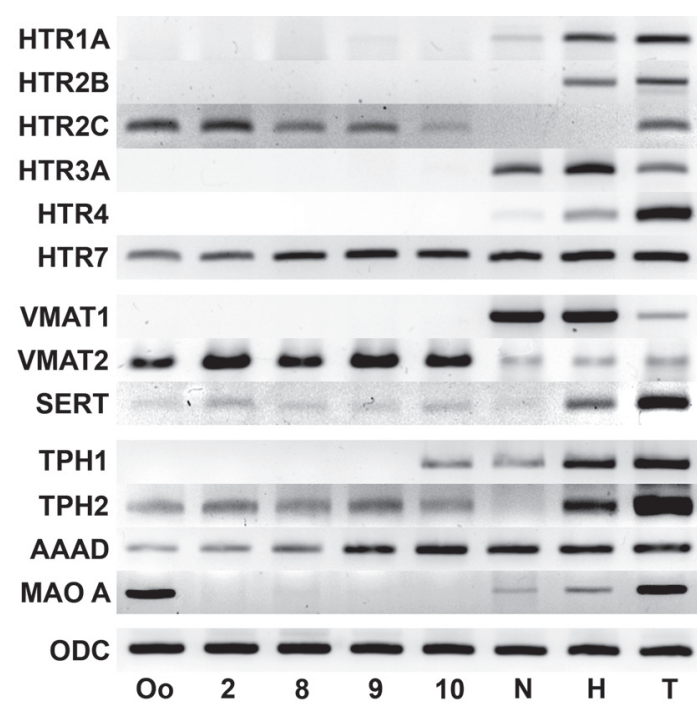

Fig. 1. Temporal expression of serotonergic system components during Xenopus laevis development. The serotonin receptors HTR2C and HTR7, vesicular transporter VMAT2, sodium-dependent transporter SERT, enzymes of synthesis TPH2 and AAAD are expressed during the early stages of development. The MAOA expression detected in oocytes is due to the jelly coats (see Fig. 8 and Discussion). Abbreviations: Oo, oocyte; 2, 2-cell embryo (stage 2); 8, midblastula (stage 8); 9, late blastula (stage 9); 10, early gastrula (stage 10); $N$, neurula (stage 15); $H$, hatched larvae (stage 33-35) and T, tadpoles (stage 57). ODC is the endogenous control.

\section{Results}

\section{Serotonin receptors}

To detect the serotonin receptors involved during early Xenopus laevis embryogenesis, we performed temporal expression analysis of six types of these receptors using the known mRNA sequences. The total RNA was isolated from the embryos at different developmental stages and used for RT-PCR. The results are presented in Fig. 1. The expression of HTR2C and HTR7 was detected at the stages of oocyte, 2 blastomeres (stage 2), and midblastula, i.e., before the beginning of zygotic genome expression. The sequence of the PCR products from the oocyte stage corresponded to the $X$. laevis HTR2C and HTR7 mRNAs (data not shown). The expression of these two genes was also detected during midblastula (stage 8), late blastula (stage 9), and early gastrula (stage 10) after Xenopuszygotic genome activation. During the neurula stage, the HTR7 transcripts persisted, and the expression of HTR1A, HTR3A, and HTR4 was also detected; however, HTR2C mRNA was absent at this stage. All serotonin receptors were expressed after hatching except HTR2C. All 6 serotonin receptors were expressed during the tadpole stage.

The transcripts of at least two serotonin receptors were present within the maternal mRNA pool during the earliest stages of development. Quantitative real-time PCR was used to evaluate the levels and dynamics of their expression. The expression levels were normalized to the expression level of ornithine decarboxylase (ODC) at stage 2, which is the stage when the maternal genes are expressed exclusively. The expression level of HTR2C during stage 2 was approximately $0.002 \%$ of that of ODC (Fig. 2). HTR2C expression reached a maximum during the two-blastomere stage and then steadily decreased (Fig. 3) to $57.8 \%$ during stage $8,36.9 \%$ during stage 9 and $11.3 \%$ during stage 10. HTR2C expression was not detectable during the neurula and hatching stages. During stage 2, the expression of HTR7 mRNA was approximately $4.9 \%$ compared with ODC (Fig. 2). HTR7 was expressed without interruption (Fig. 3) at $96.8 \%$ during stage $8,78.2 \%$ during stage $9,72.6 \%$ during stage 10 , $78.0 \%$, during the neurula stage and decreasing to $32.2 \%$ during hatching, compared with the expression level during stage 2.

Samples of the animal caps (AC), marginal zones (MZ), and vegetal pole fragments (VP) during stage 9 were isolated to determine the relative expression of HTR2C and HTR7along the animal-vegetal axis. The real-time PCR results using these fragments are shown in Fig. 4. Compared with the AC, the HTR2C expression levels in the MZ and VC samples were $83.0 \%$ and $64.7 \%$, respectively, whereas those of HTR7 were $119.3 \%$ and $90.6 \%$, respectively. Thus, the relative levels of serotonin receptor expression along the animal-vegetal axis either did not differ (in
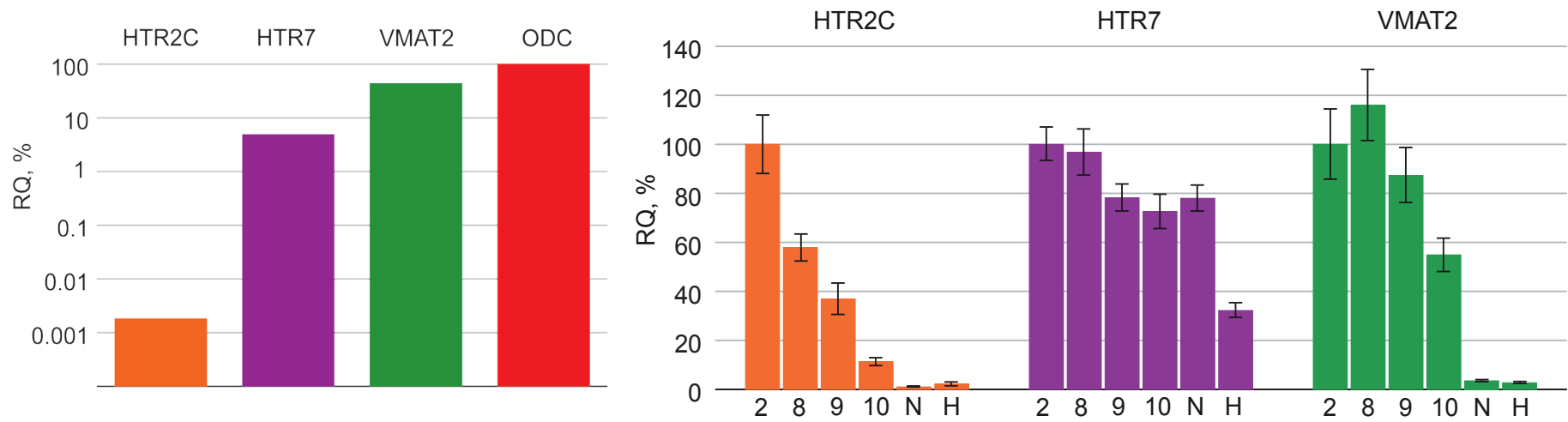

Fig. 2 (left). Relative expression levels of HTR2C, HTR7 and VMAT2 compared with ODC at the two-cell embryonic stage. Real-time PCR was performed using different primers for the same probe. The Ct values were calculated via equal threshold levels. The relative expression levels (RQ) were calculated via the efficiency-corrected $\Delta$ Ct method (Bookout et al., 2005). The ODC expression level was considered to be 100\%. The RQ for VMAT2 was approximately $43.9 \%$, HTR7 approximately $4.9 \%$, and HTR2C $0.002 \%$.

Fig. 3 (right).The mRNA expression profiles of HTR2C, HTR7 and VMAT2 during $\boldsymbol{X}$. laevis embryogenesis. The relative expression levels (RQ) were normalized to ODC expression at the 2-cell embryonic stage ( \pm SD). Abbreviations: 2, 2-cell embryo (stage 2); 8, midblastula (stage 8); 9 , late blastula (stage 9); 10, early gastrula (stage 10); N, neurula (stage 15); H, hatched larvae (stage 33-35). 

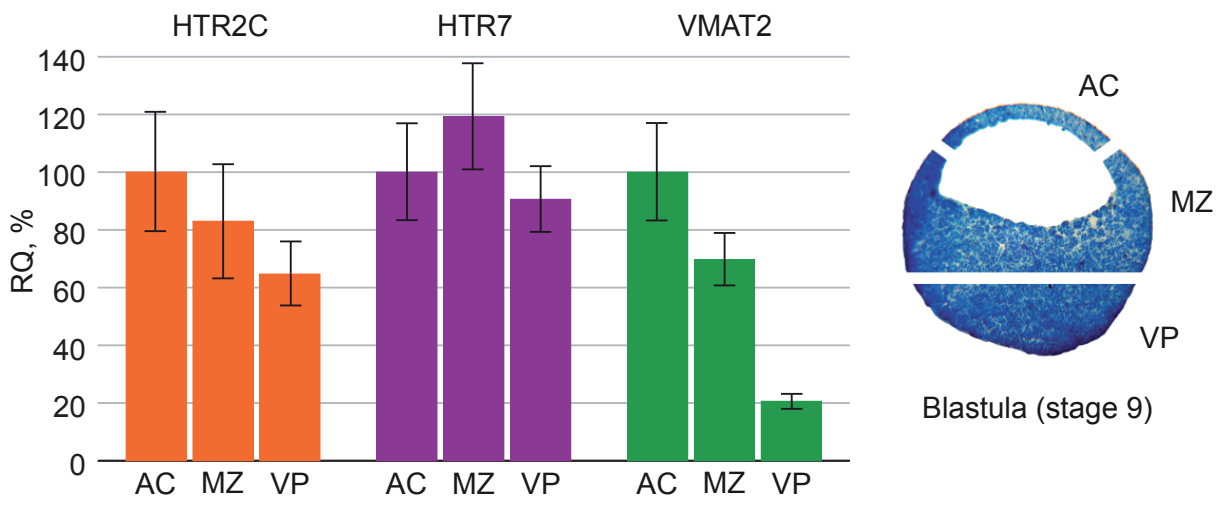

Blastula (stage 9)

Fig. 4. The spatial distribution of the mRNA expression of HTR2C, HTR7 and VMAT2 within the Xenopus blastula-stage embryo. The relative expression levels (RQ) were normalized to ODC of the AC sample $( \pm S D)$. VMAT2 expression has pronounced animal-vegetal gradient, whereas HTR2C and HTR7 expression have not. AC, animal cap; MZ, marginal zone; VP, vegetal portion of the embryo.

the case of HTR7) or the difference was statistically insignificant (in case the of HTR2C). These data are supported by the results of the in situ hybridization of HTR7 transcripts that were expressed during early embryogenesis at relatively high levels (Fig. 5). The HTR7 transcripts in the zygotes and cleavage-stage embryos were localized to the periphery, mainly in the animal area. Such localization persisted also during the blastula stage; the signal was visible in both the animal and vegetal zones but was much more intense in the AC.

\section{Serotonin transporters}

The RT-PCR analysis of the vesicular transporters during embryogenesis (Fig. 1) demonstrated that VMAT1 was expressed during neurulation, hatching and tadpole stage, whereas it was absent at the earlier developmental stages. VMAT2 was expressed throughout embryonic development but at very low levels after stage 10. The VMAT2 PCR product obtained from the samples of oocytes was isolated and sequenced. The sequence obtained corresponded to that of $X$. laevis VMAT2 mRNA.

We examined the gene expression profiles of VMAT2 during $X$. laevis development using real-time PCR. The VMAT2 expression level during stage 2 was approximately $43.9 \%$ compared with that of ODC (Fig. 2). Until gastrulation, VMAT2 expression remained relatively constant: $115.9 \%$ during the midblastula stage and $87.3 \%$ during the late blastula stage compared with stage 2 , and then it decreased to $54.9 \%$ during early gastrulation and decreased sharply to $3.5 \%$ during neurulation, and to $2.7 \%$ during the post-hatching stage (Fig. 3 ).

Real-time PCR using the AC, MZ, and VC samples was performed to study the animal-vegetal distribution of VMAT2 expression (Fig. 4). The VMAT2 expression level in the MZ and VPsamples achieved $69.7 \%$ and $20.6 \%$, respectively, compared with that of the AC. Thus, VMAT2 expression had a pronounced animal-vegetal gradient. We performed an in situ hybridization of VMAT2 (Fig. 5) and obtained a more pronounced expression within the $A C$ of the blastula as well as within the animal area of the zygote and cleavage-stage embryo.

The research would not be complete without a similar analysis of the serotonin transporter SERT. However, the SERT sequence of $X$. laevis was unknown. Therefore, we analyzed the SERT mRNA sequences of $X$. tropicalis and Danio and selected primers for the regions of $X$. tropicalis SERT mRNA that were maximally homologous to Danio SERT mRNA (see Fig. 6). RTPCR using these primers produced a poorly expressed product in all samples obtained before the hatching stage (Fig. 1). The PCR product was isolated from the oocytes and sequenced (GeneBank ID: JQ001861) to demonstrate that SERT was expressed during the early developmental stages. The sequence of the PCR product and its alignment with the sequence of that of $X$. tropicalis is shown in Fig 6. The comparison indicates that there are 17 nucleotide substitutions, 4 of which were non-synonymous and only one of which was non-conservative. Thus, the expression of SERT was confirmed during the early stages of Xenopus embryogenesis.

\section{Enzymes of serotonin synthesis and degradation}

Unlike AAAD and TPH1, the sequence of TPH2 mRNA of $X$. laevis is unknown. We analyzed the $X$. laevis EST database and located the sequence derived from the adult eye (CF547701), which was homologous to TPH2. The expression of these genes was analyzed during embryogenesis using RT-PCR (Fig. 1). $\mathrm{TPH} 1$ was not expressed during early embryogenesis and only appeared during stage 10. TPH2 was expressed during all of the stages studied, although the levels of expression were low from the oocyte to hatching stage. AAAD was expressed throughout development.

To confirm the maternal origin of embryonic serotonin and discover the source of its synthesis, a PCR analysis of the corresponding enzymes within the Xenopus ovary was performed (Fig. 7). All enzymes that are required for serotonin synthesis
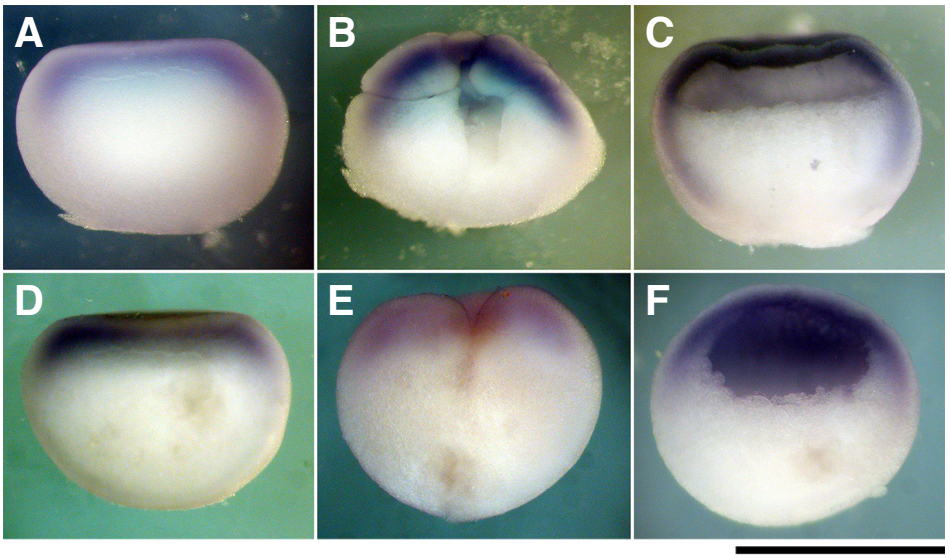

$1000 \mu \mathrm{m}$

Fig. 5. Pattern of expression of HTR7 andVMAT2 mRNA during early Xenopus embryogenesis. In situ hybridization for (A-C) HTR7 and (D-F) VMAT2 to oocytes (A,D), cleavage embryos (B,E) and blastula (C,F). The animal-vegetal gradient of distribution was detected both for the VMAT2 and HTR7 transcripts. During the blastula stage, the VMAT2 transcripts were localized mainly to the animal hemisphere, whereas the HTR7 transcripts were also present in the vegetal hemisphere. 
mRNA:

1 AACACTCCTAACTGCACCAACTACTTTGGCAAATCTAACATAACCTGGAACAATTATTCTAAATCTCCAG X. laevis 412 AACACTCCTAACTGCACCAACTACTTTGGCAGGTCTAACATTACCTGGAACAATTACTCAAAGTCCCCAG X. tropicalis 521 AACACCGAAAACTGCACCAACTACTTTGGCAAAGACAACGTGACCTGGACCAACTATTCACGTTCACCCG Danio

71 CAGAAGAgTTTTATACGAGAAAAGTCCTTGGAATTCATGAAGCAGACGGCTTAGATGATGTTGGAGGCTT $\mathbf{X}$. laevis 482 CTGAAGAGTTTTATACGAGAAAGGTCCTTGGAATTCATGAAGCAGAAGGCTTGGACAATGTAGGAGGCTT $X$. tropicalis 591 CCGAGGAGTTTTACACGAGGAATGTCCTGGCCGTGCATGAATCCTCTGGGCTTGGTAATGTGGGCTACAT Danio

141 ACGCTGGCAGCTGCTTCTCTGCCTTTTTATAATATTTACCATTGTATACTTCAGTTTGTGGAAAGGAGTG

552 ACGCTGGCAGCTGATTCTCTGCCTGTTTATCATATTTACCATTGTA

661 TCGCTGGCAGCTCATGCTCTGTCTCTTCCTCATCTTCACCATtGTCTACTTCAGCCTGTGGAAAGGAGTC Danio

Protein:

1 NTPNCTNYFGKSNITWNNYSKSPAEEFYTRKVLGIHEADGLDDVGGLRWQLLLCLFIIFTIVYFSLWKGV X.laevis 138 NTPNCTNYFGRSNITWNNYSKSPAEEFYTRKVLG I HEAEGLDNVGGLRWQLILCLFI IFTIVYFSLWKGV X.tropicalis

164 NTENCTNYFGKDNVTWTNYSRSPAEEFYTRNVLAVHESSGLGNVGY IRWQLMLCLFLIFTIVYFSLWKGV Danio

NNN XXX - matched whith $X$. tropicalis NNN XXX - differed from $X$. tropicalis

NNN - forward SERT primer location - reverse SERT primer location

Fig. 6. Alignment of SERT mRNA and the appropriate protein sequences. The PCR product of X. laevis SERT (JQ001861) and the deduced protein sequence were aligned via the ClustalW method with X. tropicalis SERT mRNA (XM_002932084) and protein (XP_002932130) as well as the Danio SERT mRNA (NM_001177459) and protein (NP_001170930). The primers were designed to X. tropicalis SERT mRNA regions that were the most similar to that of Danio. 17 nucleotides differed between the nucleotide sequences of $\mathrm{X}$. laevis and $\mathrm{X}$. tropicalis SERT is, but the protein sequence had only 4 substitutions.

were expressed within the ovary (both types of TPH and AAAD). To determine the source of embryonic serotonin, the expression of the aforementioned enzymes was investigated in the samples from the follicle envelope and immature oocytes (stages I - III) (Fig. 7). AAAD was expressed in the immature oocytes as well as in the follicle envelope. TPH1 was detected in the follicle envelope but not in the oocyte, whereas TPH2 was expressed in the oocytes but not in the follicle envelope.

Finally, we performed a temporal expression analysis of MAOA (Fig. 1). This gene was distinctly expressed in mature oocytes, but its transcripts could not be detected between stage 2 and stage 10. MAOA was then expressed during the neurula stage and also during the hatching and tadpole stages. This difference in expression between the oocyte and 2-blastomere stage embryo required additional analysis. Samples of the oocytes for these experiments were obtained directly from a female frog without avoiding the jelly coat (most likely contaminated with some cells from the genital tract), in contrast to other samples. Therefore, the samples of RNA were obtained from dejellied oocytes and jelly coat material and used for additional RT-PCR analysis (Fig. 8). MAOA expression was detected in jelly coat material but was absent in dejellied oocytes. Hence, we concluded that MAOA was not expressed during the early stages of $X$. laevis embryogenesis.

\section{Discussion}

The present research showed a complex expression pattern of the of serotonin receptors during Xenopus laevisembryonic and larval development. According to Xenbase (www.xenbase.org), there are 15 main types of serotonin receptors in the Xenopus tropicalis genome. However, for $X$. laevis, the mRNA sequences of only 6 serotonin receptors are known.

We have shown that two of these receptors, HTR2C and HTR7, are expressed during the earliest stages of $X$. laevis embryogenesis. Interestingly, the expression levels of these receptors differ quantitatively; there are 2500-fold more HTR7 transcripts than those of HTR2C. It is known that transcription process is absent until Xenopus midblastula stage, and protein synthesis occurs using the maternal mRNA accumulated during oogenesis (Heasman, 2006). Thus, the transcripts of these two serotonin receptors are a part of the pool of maternal mRNA. It is logical to suggest that the prenervous functions of serotonin are mediated by receptors $5-\mathrm{HT}_{2 \mathrm{C}}$ and $5-\mathrm{HT}_{7}$ during early $X$. laevis embryogenesis. On the other hand, the maternal mRNA may also be translated at later stages, even after the midblastula transition (activation of the zygotic genome). Of course, mRNA expression does not guarantee the production of the corresponding protein during the early stages of Xenopus embryogenesis. However, the dynamics of RNA expression can provide insight regarding the function of the corresponding gene.

We demonstrated that the expression dynamics of these receptors differed greatly. HTR7 expression remained at an even level until hatching, whereas the expression of HTR2C constantly decreased and disappeared by the neurula stage. Therefore, it is possible that the $5-\mathrm{HT}_{2 \mathrm{C}}$ receptor is involved in the early prenervous processes whereas the $5-\mathrm{HT}_{7}$ receptor can be functional throughout development. This possiblility is supported by the ability of $5-\mathrm{HT}_{2 \mathrm{~A}}$ and $5-\mathrm{HT}_{2 \mathrm{C}}$ antagonist ritanserine to induce the germinal vesicle breakdown in the immature Xenopusoocytes (Sheng etal., 2005). It is important that $5-\mathrm{HT}_{2 \mathrm{C}}$ and $5-\mathrm{HT}_{7}$ receptors are coupled to different systems of second messengers; the $5-\mathrm{HT}_{2 \mathrm{C}}$ receptor activates the phosphatidylinositol signal pathway, whereas the $5-\mathrm{HT}_{7}$ receptor activates the adenylate cyclase signaling pathway (Peroutka, 1997). The activation of these signal cascades has various consequences, such as changing the state of the cytoskeleton (Larsson, 2005)

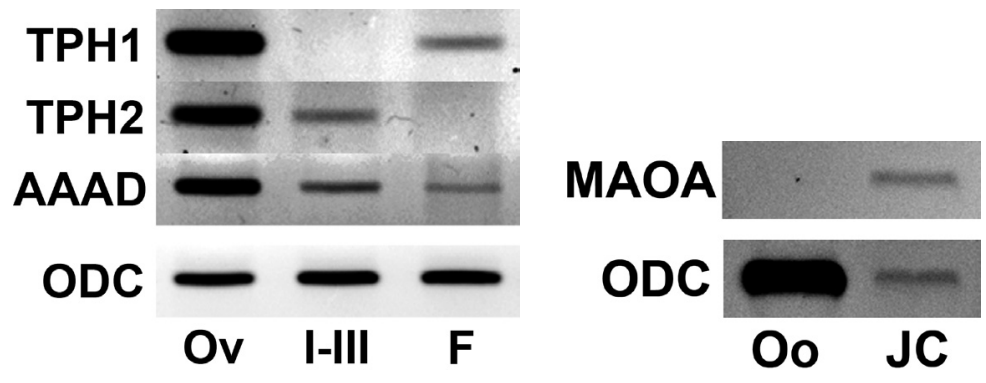

Fig. 7 (left). Expression of serotonin synthesis enzymes in Xenopus ovaries. I-III, immature oocytes (stages I-III); AAAD, aromatic aminoacid decarboxylase; $F$, follicular envelope; Ov, total ovary; TPH, tryptophan hydroxylase.

Fig. 8 (right). Expression of monoamine oxidase A (MAOA) in dejelled Xenopus oocytes and jelly coats. JC, jelly coat (which can comprise the cells from the female genital tract); Oo, dejellied oocytes. MAOA is not expressed in the dejellied oocytes but is present in the material obtained upon dejelling. 
TABLE 1

\section{ACCUMULATED MOLECULAR BIOLOGY DATA ON THE EXPRESSION OF TRANSMITTER RECEPTORS DURING THE EARLY EMBRYOGENSIS OF VARIOUS SPECIES}

\begin{tabular}{lcl} 
Species & Gene & Reference \\
\hline Mouse & HTR1D & Vesela et al., 2003 \\
Mus musculus & HTR5 & Hinckley et al., 2005 \\
& HTR7 & Amireault, Dube, 2005b \\
& H-AdR & Čikoš et al., 2005 \\
Caenorhabditis elegans & HTR2C & Hamdan et al., 1999 \\
Danio rerio & HTR1A & Nikishin et al., 2009 \\
Sea urchin & HTR4 & Nikishin et al., 2012 \\
Paracentrotus lividus & nAChR $\alpha 6$ & \\
& nAChR $\alpha 10$ & \\
Clawed frog & nAChR $\alpha 7$ & Falugi et al., 2011 \\
Xenopus laevis & HTR2C & Nikishin et al., present paper \\
& HTR7 & \\
& $\beta-A d R$ & Devic et al., 1997
\end{tabular}

and setting up the axial complex (Kim, Han, 1999).

Other serotonin receptors that have been studied are not expressed during the early stages of development. HTR1A is detectable beginning at late blastula stage, HTR3A and HTR4 beginning at the neurula stage, and HTR2B after hatching. The entire set of serotonin receptors is expressed at the tadpole stage only. Pharmacological and immunohistochemical data support the possible participation of $5-\mathrm{HT}_{3}$ and $5-\mathrm{HT}_{4}$ receptors in establishing the left-right asymmetry in Xenopus (Fukumoto et al., 2005b). The $5-\mathrm{HT}_{3}$ receptor is a ligand-dependent ionic channel whose functional activity is associated with the presence of HTR3A-subunits (Boyd et al., 2002). Therefore, the absence of HTR3A expression during early embryogenesis results in the absence of de novo formation of the functional $5-\mathrm{HT}_{3}$ receptors at this stage. The controversy between our data and those reported by Fukumoto et al., (2005b) can be explained by the difference in the sensitivity between mammalian and amphibian serotonin receptors to the same ligands. Fukumoto et al., (2005b) also reported the presence of HTR4 transcripts during the early stages of the development using in situ hybridization (ISH). Taking into account the higher specificity and sensitivity of RT-PCR compared with ISH, a false-positive result of the ISH is more probable than a false-negative RT-PCR result.

It is intriguing that we found a wide diversity of serotonin receptor types that are expressed during early development (Table 1) when summarizing both our data and the literature data, with a few coincidences - the 5- $\mathrm{HT}_{2 \mathrm{C}}$ in Xenopus and $C$. elegans, and the $5-\mathrm{HT}_{7}$ in Xenopus and mouse. It is possible to reliably predict that serotonin receptors are also expressed in the embryos of species not yet studied in this regard, similarly to serotonin and other transmitters that were discovered in embryos of all species investigated. However, the types of serotonin receptor evidently are not strictly determined, although their mechanisms would be highly conserved. Furthermore, serotonin receptors do not encompass possible transmitter mechanisms in embryo because, both in Xenopus (Devic et al., 1997) and mouse (Čikoš et al., 2005), the $\beta$-adrenoreceptors ( $\beta$-AdR) and serotonin receptors are expressed simultaneously (Table 1). A similar situation occurs during the early development of sea urchins where homologs of HTR4 and the $\alpha_{6}-$ and $\alpha_{10}$-subunits of nicotinic acetylcholine receptor (nAChR) are simultaneously expressed (Nikishin et al., 2012).

Transporters are equally important components of the serotoner- gic system, although there are few data on their presence during early embryogenesis. The expression of the vesicular monoamine transporter during the early developmental stages was first shown in the present work. VMAT2 transcripts are present in the maternal mRNA pool where their amount is half of that of the house-keeping gene ODC. The more pronounced VMAT2 expression in the animal part of the embryo, where the most active cleavage divisions and morphogenetic processes occur, suggests the involvement of vesicular transport in these processes. A number of vesicular structures, where serotonin and other biogenic monoamines can be accumulated, are present in the embryonic cells.

Furthermore, we have shown that SERT is expressed during entire embryogenesis, although at low levels until hatching. SERT is expressed in the mammalian preimplantation embryos and is capable of serotonin uptake from the intercellular space into the cytosol (Amireault, Dube, 2005a; Basu et al., 2008). This may take place in Xenopus and is supported by the pharmacological and molecular-genetic experiments demonstrating the participation of VMAT and SERT in establishing the left-right asymmetry (Fukumoto et al., 2005a).

Serotonin biosynthesis includes two stages involving tryptophan hydroxylase (TPH) and the aromatic aminoacid decarboxylase (AAAD). The dynamics of the serotonin concentration during Xenopus embryogenesis suggest that the level of serotonin is maximal in the zygote and then falls to a minimum at hatching (Fukumoto et al., 2005b). We have shown that AAAD is expressed at all stages; however, TPH2 is expressed weakly during early embryogenesis and TPH1 only after hatching. This result indicates that embryonic serotonin can be synthesized during early embryogenesis, although at low levels.

We have shown in the present work that the synthesis of serotonin, accumulated in the oocyte, may occur in the follicle envelope with the participation of TPH1. Oocytes and follicle cells interact during oogenesis and are coupled via gap junctions that allow the exchange of substances of a low molecular weight (Zhang, Levin, 2009). Besides, blood vessels and nervous terminals may be an additional source of exogenous serotonin. We have shown that SERT is expressed in oocytes, i.e., the accumulation of serotonin may occur as a result of its reuptake from the intercellular space.

It is known that the main pathway of serotonin degradation is its enzymatic oxidation by monoamine oxidase A (Shih et al., 1999). The MAOA mRNA expression was not detected in dejellied oocytes, whereas it was detected in the intact oocytes and in the material obtained upon their dejelling. Therefore, it is possible that the source of MAOAmRNA in the samples of intact oocytes may be cells from the female genital tract. MAOA is not expressed during early embryogenesis until the neurula stage. This is in agreement with the earlier data on low levels of MAO activity during early development (Baker, Quay, 1969). It is important that another mechanism of serotonin inactivation exists in the embryonic cells to transport the transmitter from the cytosol to the extracellular medium (see Buznikov, 1990).

Therefore, a question arises regarding the physiological meaning of the set of transporters expressed during early embryogenesis. On one hand, these transporters are usually required for the canonical serotonergic mechanism that may also participate in the cellular interactions during early embryogenesis (Shmukler, Buznikov, 1998). On the other hand, transporters can participate in the embryonic functions of serotonin (regulation of the cell cycle 
TABLE 2

SPECIFIC OLIGONUCLEOTIDES USED IN THE PRESENT WORK

\begin{tabular}{|c|c|c|c|c|c|c|}
\hline Gene & GenBank ID & Sequences of oligonucleotides & $\mathrm{T}_{\mathrm{ann}},{ }^{\circ} \mathrm{C}$ & Elongation, s & Product length, bp & $\mathrm{N}$ of cycles \\
\hline \multicolumn{7}{|c|}{ (A) Primers for RT-PCR } \\
\hline ODC & NM_001086698 & $\begin{array}{l}\text { GCCATTGTGAAGACTCTCTCCATTC } \\
\text { TTCGGGTGATTCCTTGCCAC }\end{array}$ & 60.0 & 15 & 221 & 40 \\
\hline HTR1A & NM_001085830 & $\begin{array}{l}\text { TTATCTCCTTGGACGTGTTGTGTT } \\
\text { AGCGGGCTGCCTTGAATA }\end{array}$ & 56.8 & 30 & 336 & 40 \\
\hline HTR2B & NM_001089275 & $\begin{array}{l}\text { GAAATGCTGGCTGGCTCTGC } \\
\text { CTGCGGTGGCTTGTTCTTGATTA }\end{array}$ & 56.0 & 45 & 616 & 40 \\
\hline HTR2C & AJ549931 & $\begin{array}{l}\text { TTGCCAGTTATATCCGTTGTC } \\
\text { AGTCCCAGGTTGCATTTCTAT }\end{array}$ & 50.4 & 15 & 194 & 40 \\
\hline HTR3A & NM_001086077 & $\begin{array}{l}\text { ACGGCCAAATGTCCCTAACT } \\
\text { TGCCCAAACAATAATAAGAATA }\end{array}$ & 50.8 & 30 & 391 & 40 \\
\hline HTR4 & AY583535 & $\begin{array}{l}\text { CAGCCTCCATCCTTCATCTTTG } \\
\text { GGCATAGGGCTTGTTCACCAT }\end{array}$ & 54.0 & 30 & 266 & 40 \\
\hline HTR7 & NM_001085784 & $\begin{array}{l}\text { GACAAGCTCCCGCCTAAGAAGAAT } \\
\text { GTAGCCGAGCCACAGAAGAGTCCT }\end{array}$ & 57.4 & 30 & 270 & 40 \\
\hline VMAT1 & NM_001085945 & $\begin{array}{l}\text { ATCCATTTGGCTGCACATCTCATA } \\
\text { CCCACTCGCACATTCTCTTCATTT }\end{array}$ & 55.2 & 30 & 441 & 40 \\
\hline VMAT2 & NM_001086569 & $\begin{array}{l}\text { AGAGACGGCCTTTCCAGA } \\
\text { CACTCCAGCCCCTATACATTACAT }\end{array}$ & 51.0 & 30 & 365 & 40 \\
\hline SERT & XM_002932084 & $\begin{array}{l}\text { AACACTCCTAACTGCACCAACTAC } \\
\text { CACTCCTTTCCACAAACTGAAGTA }\end{array}$ & 52.0 & 15 & 210 & 45 \\
\hline TPH1 & NM_001087454 & $\begin{array}{l}\text { GGCCGGGCTGCTTTCTTCTA } \\
\text { ACCCCGAGCTGCTTGTTCATC }\end{array}$ & 54.4 & 30 & 339 & 40 \\
\hline TPH2 & CF547701 & $\begin{array}{l}\text { AATGTATTATCACCGACTTTCAG } \\
\text { TGTTTTAGATCACTCCTTA }\end{array}$ & 46.0 & 15 & 205 & 45 \\
\hline AAAD & NM_001110741 & $\begin{array}{l}\text { TCTTCGGACCAGGCACACTCAT } \\
\text { CTACCAGCATAAGCCGCATCAATA }\end{array}$ & 55.0 & 30 & 272 & 40 \\
\hline MAOA & NM_001094885 & $\begin{array}{l}\text { AACTGCCATCAATAAGGAACCA } \\
\text { CAGGAGGGAAATATGCAGTATAAC }\end{array}$ & 53.0 & 30 & 384 & 40 \\
\hline \multicolumn{7}{|c|}{ (B) Primers for real-time PCR } \\
\hline ODC & NM_001086698 & $\begin{array}{l}\text { GCCATTGTGAAGACTCTCTCCATTC } \\
\text { TTCGGGTGATTCCTTGCCAC }\end{array}$ & 60.0 & 60 & 221 & 40 \\
\hline HTR2C & AJ549931 & $\begin{array}{l}\text { AGAGCATTTGCCAGTTATATCCGTTGTC } \\
\text { CATTTCTATTGCTTCCTCTGTTTCATCCA }\end{array}$ & 60.0 & 60 & 189 & 40 \\
\hline HTR7 & NM_001085784 & $\begin{array}{l}\text { GGACCTGGTTGGGGGAGAATG } \\
\text { CGGGATACGTTAAAGGGCGAGTT }\end{array}$ & 60.0 & 60 & 152 & 40 \\
\hline VMAT2 & NM_001086569 & $\begin{array}{l}\text { ACGGAGTGCTACGAGGGGAAGGA } \\
\text { GGCAAAGGCAAACATGATAGTGGAGA }\end{array}$ & 60.0 & 60 & 195 & 40 \\
\hline \multicolumn{7}{|c|}{ (C) Primers for in situ hybridization } \\
\hline VMAT2 & NM_001086569 & $\begin{array}{l}\text { ACAGAGTATGGGAAAGGAAACACA } \\
\text { AACAAACTCATACATGGCAGAACC }\end{array}$ & 54.8 & 60 & 546 & 40 \\
\hline
\end{tabular}

and the state of cytoskeleton) where the embryonic transmitter itself and its receptor are both localized intracellularly (Buznikov, 1967, 1990). In the absence of enzymatic transmitter degradation, the transporters, whose mRNA expression were demonstrated in the present work, can inactivate the transmitter via its removal from the cytosol. Transmitter molecules that leaks into the extracellular medium can be further reutilized for the blastomere interaction.

The components of the definitive serotonergic process, such as the receptors, transporters, and enzymes of serotonin synthesis, are expressed during the early stages of Xenopus development long before the formation of nerve cells and their precursors. This system is not "the supply for future" but a part of the multifunctional system that controls a number of early developmental processes (Shmukler, Buznikov, 1998). Based on the expression pattern obtained, we suggest that the serotonergic system with certain modifications persists throughout the ontogenesis of Xenopus. Moreover, embryonic mRNA of the $5-\mathrm{HT}$ receptors are identical to those of the adult. Together with the expression of the neuronal forms of the transporters and the enzymes of serotonin synthesis, we believe that the embryonic transmitter mechanism is the ontogenetic precursor of neuronal transmitter mechanism.

\section{Materials and Methods}

\section{Probe preparation and RNA isolation}

Xenopus laevis embryos were obtained by in vitro fertilization and staged according to the tables of normal development by Nieuwkoop and Faber. The embryos were dejellied in $2 \%$ cysteine, $\mathrm{pH} 8$ and then cultured in 0.1X MMR. For temporal expression analysis, unfertilized oocytes were obtained and fixed immediately, whereas for MAOA expression analysis, the oocytes were activated and dejellied. The jelly coat samples were obtained via washout centrifugation for 5 minutes at $5000 \mathrm{~g}$. Immature oocytes were dissected from the ovary, and the follicular envelopes were removed by using crude collagenase (Sigma-Aldrich) at $2 \mu \mathrm{g} / \mathrm{ml}$ for $1 \mathrm{~h}$ at $37^{\circ} \mathrm{C}$. The samples were fixed in a ten-fold volume of RNAlater (Ambion), and the total RNA was isolated using TRI Reagent (Sigma), according to the manufacturer's instructions, and treated with DNase I (Fermentas) to remove the genomic DNA.

\section{Reverse transcription, PCR and quantitative real-time PCR}

$1 \mu \mathrm{g}$ of RNA was used for CDNA synthesis by M-MLV reverse transcriptase (Silex) and random hexanucleotides (Silex). The PCR was performed on an amplificator MJ Mini (BioRad) using ColoredTaq-polymerase (Silex) and specific oligonucleotides (Lytech) using the parameters that were selected considering the sequence of the primers and the length of the 
product (see Table 2). To exclude false-positive results, negative controls were included (PCR without reverse transcription and PCR without CDNA). The PCR products were analyzed by $1.5 \%$ agarose gel electrophoresis with ethidium bromide $(0.5 \mu \mathrm{g} / \mathrm{ml})$. Real-time PCR was performed using a 7500 Real-Time PCR System (Applied Biosystems) and EVA-Green/ROX reaction mixture (Syntol). The relative expression levels were calculated using the efficiency-corrected $\Delta \Delta \mathrm{Ct}$ method (Bookout et al., 2005). The primers were designed by Lasergene PrimerSelect (DNASTAR) using sequences from the NCBI GeneBank databases (Table 2 A,B). The primer sequences for $O D C$ that was used as endogenous control were obtained from Nandadasa et al., (2009).

\section{In situ hybridization}

The full-length coding sequence of HTR7 was amplificated using the primer sequences from Sheng et al., (2005). The PCR product (1290 bp) was cloned into the pGEM-T vector (Promega). A 3' fragment length of 780 bp was then deleted using the Sall endonuclease, and the pGEM-HTR7-5' vector was circularized using T4 ligase. The partial coding sequence of VMAT2 (546 bp) was amplified (see primers in Table $2 \mathrm{C}$ ). pGEM-VMAT2 was obtained by cloning this PCR product into pGEM-T (Promega). pGEMHTR7-5' and pGEM-VMAT2 were used for synthesizing digoxygenin-labeled riboprobes. The hybridization was performed as previously described by Harland (1991), including negative control with sense riboprobe.

\section{Sequencing}

Sequencing was performed using the same primers as for PCR in both directions using the ABI PRIZM 3100 with the BigDye v1.1 kit (Applied Biosystems) and followed by the analysis and alignment of the sequences using the bioinformation software Lasergene (DNASTAR).

\section{Acknowledgements}

The authors are grateful to Dr. N.S.Mugue for his invaluable help in the organization of sequencing and to Dr. A.S.Mikaelyan for his advice on the molecular biology methods and generous support. This work was supported by the Russ. Fund for Basic Research grant 11-04-01469-a for D.N. and Y.S.

\section{References}

ALUIGI MG, DIASPRO A, RAMOINO P, RUSSO P, FALUGI C. (2012). The sea urchin, Paracentrotus lividus, as a model to investigate the onset of molecules immunologically related to the $\alpha-7$ subunit of nicotinic receptors during embryonic and larval development. Curr Drug Targets. 13: 587-593.

AMIREAULTP, DUBÉ F. (2005a). Serotonin and its antidepressant-sensitive transport in mouse cumulus-oocyte complexes and early embryos. Biol Reprod73:358-365.

AMIREAULT P, DUBÉ F. (2005b). Intracellular CAMP and calcium signaling by serotonin in mouse cumulus-oocyte complexes. Mol Pharmacol 68: 1678-1687.

BAKER PC, QUAY WB. (1969). 5-hydroxytryptamine metabolism in early embryogenesis, and the development of brain and retinal tissues. Brain Res 12: 272-295.

BASU B, DESAI R, BALAJI J, CHAERKADY R, SRIRAM V, MAITI S, PANICKER MM. (2008). Serotonin in pre-implantation mouse embryos is localized to the mitochondria and can modulate mitochondrial potential. Reproduction 135:657-669.

BOOKOUT AL, CUMMINS CL, MANGELSDORF DJ. (2005). High-throughput realtime quantitative reverse transcription PCR. In Current protocols in molecular biology (Eds. Ausubel, F.A., Brent, R., Kingston, R.E., Moore, D.D., Seidman, J.G., Smith, J.A., and Struhl, K.) John Wiley \& Sons, New York pp. 15.8.1-15.8.21.

BOYD GW, LOWP, DUNLOPJI, ROBERTSON LA, VARDYA, LAMBERT JJ, PETERS JA, CONNOLLY CN. (2002) Assembly and cell surface expression of homomeric and heteromeric 5-HT3 receptors: the role of oligomerization and chaperone proteins. Mol Cell Neurosci 21: 38-50.

BUZNIKOV GA. (1967). Low-molecular regulators of embryonic development. Science, Moscow. (in Russian). 265 pp.
BUZNIKOV GA. (1990). Neurotransmitters in Embryogenesis. Harwood Academic Publ., Chur.

BUZNIKOV G.A. (2007). Preneural transmitters as regulators of embryogenesis. Current state of the problem. Russ. J. Dev. Biol 38: 213-220.

ČIKOŠ Š, VESELÁ J, IL'KOVA G, REHÁK P, CZIKKOVÁ S, KOPPEL J. (2005). Expression of beta adrenergic receptors in mouse oocytes and preimplantation embryos. Mol Reprod Dev 71: 145-153.

DEVIC E, PAQUEREAU L, STEINBERG R, CAPUT D, AUDIGIER Y. (1997). Early expression of a beta1-adrenergic receptor and catecholamines in Xenopusoocytes and embryos. FEBS Lett 417: 184-190.

FUKUMOTO T, BLAKELY R, LEVIN M. (2005a). Serotonin transporter function is an early step in left-right patterning in chick and frog embryos. Dev Neurosci 27: 349-363.

FUKUMOTO T, KEMA IP, LEVIN M. (2005b). Serotonin signaling is a very early step in patterning of the left-right axis in chick and frog embryos. Curr Biol 15: 794-803.

HAMDANFF, UNGRIN MD, ABRAMOVITZM, RIBEIROP. (1999). Characterization of a novel serotonin receptor from Caenorhabditis elegans: cloning and expression of two splice variants. J Neurochem 72: 1372-1383.

HARLAND RM.(1991). In situ hybridization: an improved whole-mount method for Xenopus embryos. Methods Cell Biol 36: 685-695.

HEASMAN J. (2006). Patterning the early Xenopus embryo. Development 133 1205-1217.

HINCKLEY M, VACCARI S, HORNER K, CHEN R, CONTI M. (2005). The G-proteincoupled receptors GPR3 and GPR12 are involved in cAMP signaling and maintenance of meiotic arrest in rodent oocytes. Dev Biol 287: 249-261.

KIM MJ, HAN JK. (1999). The involvement of cAMP signaling pathway in axis specification in Xenopus embryos. Mech Dev 89: 55-64.

LARSSON C. (2005). Protein kinase $C$ and the regulation of the actin cytoskeleton. Cell Signal 18: 276-284.

NANDADASA S, TAO Q, MENON NR, HEASMAN J, WYLIE C. (2009). N- and $\mathrm{E}$-cadherins in Xenopus are specifically required in the neural and non-neura ectoderm, respectively, for F-actin assembly and morphogenetic movements. Development 136: 1327-1338.

NIKISHIN DA, IVASHKIN EG, MIKAELYAN AS, SHMUKLER YB. (2009). Expression of serotonin receptors during early embryogenesis. Simpler Nervous Systems, IX East European Conference of the International Society for Invertebrate Neurobiology pp. 70 (Abstr).

NIKISHIN DA, SEMENOVA MN, SHMUKLER YB. (2012). Expression of transmitters receptors during early development of sea urchin Paracentrotus lividus. Rus J.Dev Biol 43: 181-184

PEROUTKA SJ. (1997) 5-Hydroxytryptamine receptor subtypes. In Serotonin Receptors and their Ligands (Eds. B. Olivier, I. van Wijngaarden and W. Soudijn) Elsevier Science B.V., pp. 3-13.

SCHUFF M, RÖSSNER A, DONOW C, KNÖCHEL W. (2006). Temporal and spatial expression patterns of FoxN genes in Xenopus laevis embryos. Int $\mathrm{J}$ Dev Biol 50: $429-434$

SHENG Y, WANG L, LIU XS, MONTPLAISIR V, TIBERI M, BALTZ JM, LIU XJ. (2005). A serotonin receptor antagonist induces oocyte maturation in both frogs and mice: evidence that the same $\mathrm{G}$ protein-coupled receptor is responsible for maintaining meiosis arrest in both species. J Cell Physiol 202: 777-786.

SHIH JC, CHEN K, RIDD MJ. (1999) Role of MAO A and B in neurotransmitter metabolism and behavior. Pol J Pharmacol 51: 25-29.

SHMUKLER YB, BUZNIKOV GA. (1998). Functional coupling of neurotransmitters with second messengers during cleavage divisions: facts and hypotheses. Perspect Dev Neurobiol 5: 469-480.

VESELÁ J, REHÁK P, MIHALIK J, CZIKKOVÁ S, POKORNÝ J, KOPPEL J. (2003). Expression of serotonin receptors in mouse oocytes and preimplantation embryos. Physiol Res 52: 223-228.

ZHANG Y, LEVIN M. (2009). Particle tracking model of electrophoretic morphogen movement reveals stochastic dynamics of embryonic gradient. Dev Dyn 238: 1923-1935. 


\section{Further Related Reading, published previously in the Int. J. Dev. Biol.}

Increased cellular turnover in response to fluoxetine in neuronal precursors derived from human embryonic stem cells Eun-Ah Chang, Zeki Beyhan, Myung-Sik Yoo, Kannika Siripattarapravat, Tak Ko, Keith J. Lookingland, Burra V. Madhukar and Jose B. Cibelli Int. J. Dev. Biol. (2010) 54: 707-715

Spatio-temporal expression of a Netrin homolog in the sea urchin Hemicentrotus pulcherrimus (HpNetrin) during serotonergic axon extension

Hideki Katow

Int. J. Dev. Biol. (2008) 52: 1077-1088

Serotonin involvement in the metamorphosis of the hydroid Eudendrium racemosum Giuliana Zega, Roberta Pennati, Arianna Fanzago and Fiorenza De Bernardi Int. J. Dev. Biol. (2007) 51: 307-313

Action of serotonin antagonists on cytoplasmic calcium levels in early embryos of sea urchin Lytechinus pictus

Y B Shmukler, G A Buznikov and M J Whitaker

Int. J. Dev. Biol. (1999) 43: 179-182

Activation of an $85 \mathrm{kDa}$ ribosomal $\mathrm{S} 6$ kinase during serotonin-induced oocyte maturation

Y Durocher and P Guerrier

Int. J. Dev. Biol. (1996) 40: 557-566

5 yr ISI Impact Factor $(2010)=2.961$

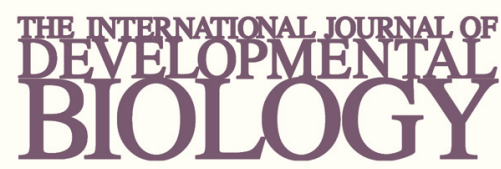

Volume 54 Nos. 6/7

Special Issue
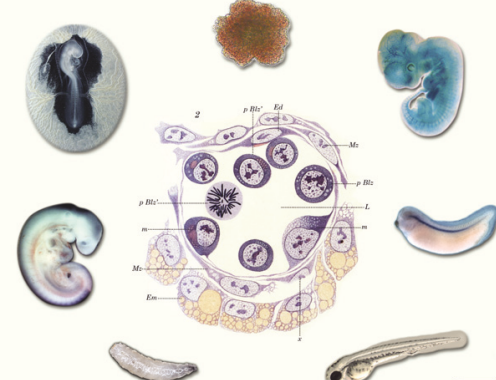

Developmental Hematopoiesis

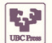

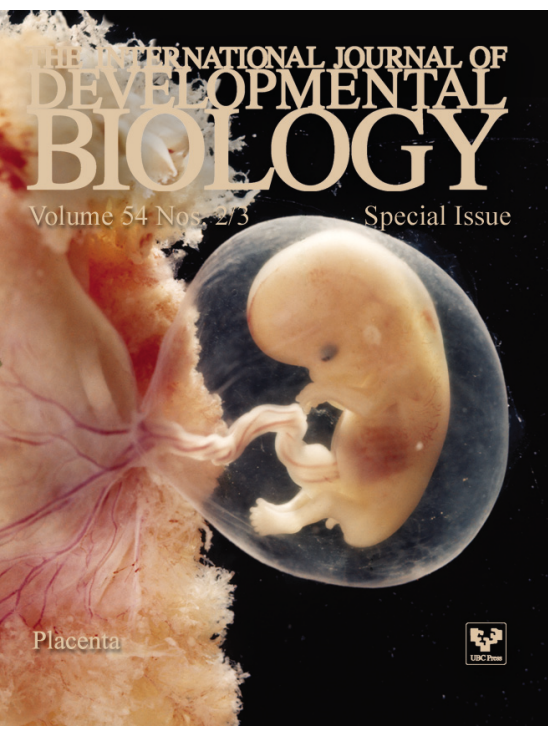
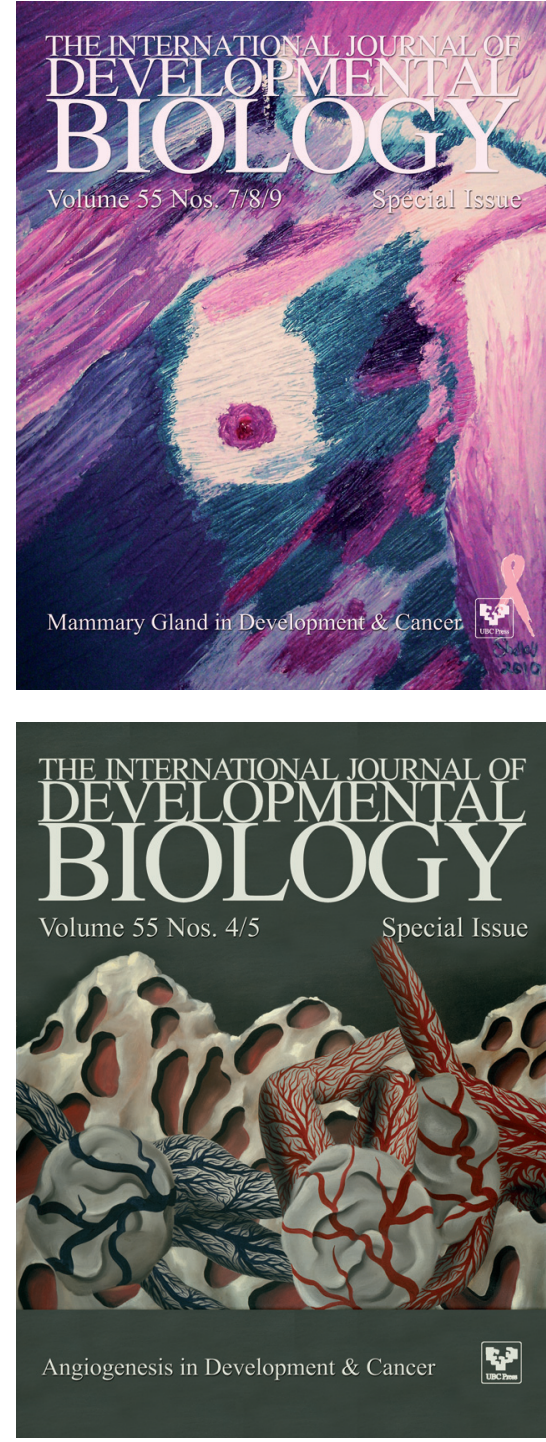